\title{
NATUREZA E DIREITO NAS INSTITUTAS DE GAIO ${ }^{1}$
}

\section{Alfredo Carlos Storck (UFRGS) ${ }^{2}$}

alfredostorck@gmail.com

Resumo: Em uma famosa passagem de suas Institutas, o jurista romano Gaio dividiu o direito privado em duas partes: o direito civil e o direito dos povos. O primeiro é o direito criado pelo povo romano enquanto o segundo é o direito seguido por todas as nações. A despeito de sua origem clássica, os especialistas discordam acerca do modo de interpretar essa tese. No início do século XX, historiadores como Michel Villey viram na distinção sinais da influência da filosofia grega (estoica e mesmo aristotélica) entre os juristas romanos. Posteriormente Levy e mais recentemente Kelly contestaram essa afirmação e defenderam que filósofos e juristas possuíam, no período clássico, noções de natureza e direito natural completamente distintas. O objetivo desse artigo não está em provar a exata influência da filosofia grega entre os juristas, mas apenas em sugerir que não é possível fornecer uma interpretação dos textos clássicos sem atribuir a eles uma concepção teórica do direito natural.

Palavras-chave: Direito Romano, Direito Natural, Gaio, natureza.

A despeito dos esforços de alguns historiadores do direito (VILLEY 1953) que buscaram realçar a importância das noções filosóficas de justiça, direito natural, natureza e lei entre os juristas romanos, continua a ser bastante aceita a existência de uma grande distância que separava juristas e filósofos na Roma Antiga. A suposta presença, nos textos jurídicos clássicos, de um vocabulário filosófico, principal-

\footnotetext{
${ }^{1}$ Recebido: 07-12-2010/Aprovado: 30-01-2011/Publicado on-line: 07-09-2011.

${ }^{2}$ Alfredo Carlos Storck é Professor-adjunto do Departamento de Filosofia da Universidade Federal do Rio Grande do Sul, Porto Alegre, Brasil e pesquisador do CNPq.
} 
mente de origem estoica, não deveria ser tomada, segundo essa interpretação, como indício de uma verdadeira influência, mas como uma mera semelhança de palavras. $O$ vocabulário jurídico clássico deveria ser sempre interpretado à luz da atitude estritamente pragmática que animava a mente dos juristas, pouco afeitos à especulação e à elaboração de regras abstratas (FASSÒ 2005). Aceita essa perspectiva, dever-se-ia abandonar, por exemplo, qualquer tentativa de encontrar ecos de teorias filosóficas acerca do direito natural entre os juristas, pois "os filósofos romanos - termo que, nesse contexto, inclui quase que somente o multifacetado Cícero - tinham um conceito de 'natureza' muito diferente do conceito dos juristas romanos; e o uso dos juristas, por sua vez, não era uniforme" (KELLY 2010, 74).

Nosso objetivo, neste artigo, não é o de provar a influência do estoicismo nos textos legais clássicos ou mesmo o de demonstrar a identidade entre "o direito natural eterno e divinamente inspirado de Cícero e o direito natural prático dos juristas" (idem, 79). Buscaremos apenas nuançar a radicalidade de uma tese que iria na direção oposta e que não reconheceria nenhum sentido abstrato para a noção de natureza tal como empregada pelos juristas. Dito de modo mais preciso, procuraremos simplesmente limitar a força de duas teses estudadas em um importante artigo por Ernst Levy (1949) e que, a nosso juízo, esvaziam completamente a noção de natureza entre os juristas. São elas: a) natural é aquilo que, dentro da estrutura de um sistema, decorre como consequência da ordem normal; b) em todo conflito entre o direito natural e o direito civil prevalece o último. Aceitas as teses, não parece difícil concluir, como o fez Douzinas $(2007,158)$, que "os juristas romanos pragmáti- 
cos identificavam o jus naturale com o direito romano", e eliminar assim a própria noção de direito natural.

\section{NATUREZA E DIVISÃO DO DIREITO PRIVADO}

A obra do jurista Gaio ( \pm 110-179 d.C.), de quem muito pouco se sabe sobre a vida, é uma das principais fontes das compilações de textos jurídicos realizadas na primeira metade do século VI d. C., sob as ordens do Imperador Romano do Oriente César Flávio Justiniano (483-565 d.C.), e que passaram a ser conhecidas, a partir do século XVI, como Corpus Iuris Ciuilis (CIC). As Institutas ${ }^{3}$, único livro do período clássico que chegou até nós de forma independente do $\mathrm{CIC}$, dividem o direito privado em três domínios: pessoas, coisas e ações. A obra é iniciada do seguinte modo:

Todos os povos, que são governados por leis e por costumes, fazem uso de um direito (ius) que em parte lhes é próprio e em parte é comum a todos os homens. $\mathrm{O}$ direito que cada povo constituiu para si mesmo lhe é próprio e chama-se direito civil (ius civile), pois é o direito próprio a cada cidade. Já o direito que a razão natural (naturalis ratio) constituiu para todos os homens é observado por todos os povos e chama-se direito dos povos, pois é o direito usado por todos os povos. O povo romano segue, portanto, um direito que em parte lhe é próprio e em parte comum a todos os homens. Assinalaremos quais são esses direitos no momento oportuno. Os direitos do povo romano são as leis, os plebiscitos, os senátus-consulto, as constituições dos príncipes, os editos daqueles que possuem o direito para publicá-los e as respostas dos prudentes. (GAIO, Institutas, 1)

Gaio não emprega aqui a expressão "direito natural" e

\footnotetext{
${ }^{3}$ Tomaremos Gaio (2003) como nosso texto de base, mas consultaremos também Gaio (1988) e citaremos as traduções de Gaio (1951). As traduções baseadas em Gaio (2003) são de nossa autoria.
} 
utiliza, como critério para uma norma pertencer ao direito dos povos, não o fato de ela ser aceita por todos, mas o de estar ligada à razão (LOPES 2004, 72). Ser aceita por todos os povos é mera decorrência, e não condição para algo pertencer ao direito dos povos. Por outro lado, o emprego que ele faz, em outras passagens das Institutas, da expressão "direito natural”, mostra claramente que Gaio não tem dificuldades em aceitar que os preceitos ditados pela razão natural compõem também o direito natural, podendo assim tomar as expressões "ius naturale" e "ius gentium" como sinônimas.

Comentando a passagem anteriormente citada, Kelly defende que, tomada isoladamente, ela poderia dar a entender que os romanos teriam se interessado pelos sistemas jurídicos de outros povos e chegado à conclusão de que existem normas compartilhadas por todas as nações. Tal interesse, todavia, jamais existiu. A expressão ius gentium deve mais propriamente ser interpretada como significando, aos olhos de Gaio, "um conjunto de normas originariamente romanas que eram aplicadas (excepcionalmente, porque em princípio o direito romano era aplicado somente a cidadãos romanos) em litígios entre estrangeiros no território romano ou entre um romano e um estrangeiro" (KELLY 2010, 81).

De fato, o ganho de importância do ius gentium parece estar ligado ao incremento das relações comerciais com outras cidades e ao maior número de estrangeiros em Roma. Ora, o direito romano era profundamente ritualístico, com exigências bastante precisas acerca do que deveria ser dito ou feito pelas partes no momento de celebrar um contrato (STEIN 1999, 12). Esse ritualismo, no entanto, dificultava as relações comerciais com outros povos e mesmo com es- 
trangeiros no interior da cidade. A solução então foi apelar para formas menos rígidas e facilmente reconhecidas por todos. A simplificação do cerimonial inerente aos contratos comerciais parece ter servido de apoio à tese segundo a qual o ius gentium é formado por regras reconhecidas por todos os povos. Por essa razão, foi possível sustentar que "os romanos não fizeram profundas reflexões sobre as diretrizes da razão natural [...]; mas simplesmente aplicaram, fora de sua esfera original, as regras romanas comuns que lhes pareceram adequadas, ou seja, as regras mais simples, minimamente técnicas e mais ou menos conformes com o senso comum e a prática dos povos vizinhos" (KELLY 2010, 81).

Consideramos, no entanto, um erro reduzir a compreensão romana do ius gentium e do ius naturale ao mero procedimento de simplificação do direito próprio romano, como se nenhum fator especulativo tivesse desempenhado qualquer função na concepção romana de ius gentium. Fosse assim, não deveríamos encontrar incongruências no modo como os juristas romanos entendiam a divisão do direito. Mas não é isso o que ocorre. $\mathrm{O}$ próprio CIC preserva, além da concepção bipartite de Gaio, outra, atribuída ao jurista Ulpiano (?-228 d.C.), cuja diferença em relação à primeira consiste precisamente na distinção entre o direito natural e o dos povos:

3. $\mathrm{O}$ direito natural é aquele que a natureza ensina a todos os animais. Logo, esse direito não é específico ao gênero humano, mas é comum a todos os animais que vivem na terra e no mar. Dele provém a união do homem e da mulher, que nós chamamos matrimônio, a procriação e educação da prole. Com efeito, todos os animais, mesmo os mais ferozes, parecem reconhecer esse direito. 4 . $\mathrm{O}$ direito dos povos é aquele do qual os homens se servem. Difere do direito natural, pois esse é compartilhado por todos os animais 
enquanto aquele é comum apenas aos seres humanos. [...] 6. O direito civil é aquele que não se afasta completamente do direito natural ou do dos povos, sem, contudo, estar completamente submetido a eles. Assim, ao acrescentarmos ou retirarmos algo do direito comum, criamos um direito particular que chamamos direito civil. (ULPIANO, Livro I das Instituições, apud Digesto I, 1)

Como se observa, o direito natural não é, para Ulpiano, algo próprio ao gênero humano, mas é compartilhado por todos os animais. Seu exemplo preferido é a reprodução e educação da prole, fato comum tanto aos seres humanos quanto aos demais animais. Já o direito dos povos limitarse-ia ao que é próprio aos homens, ao passo que o direito civil seria particular a cada cidade. Gaio e Ulpiano discordam, portanto, sobre o significado do direito natural. Ambos aceitam que as regras do direito dos povos são comuns a todos por possuírem sede na razão humana. Ulpiano é, todavia, mais explícito que seu antecessor ao tematizar as relações entre os dois tipos de direito e afirmar que as normas civis ampliam ou limitam as regras naturais. Nesse sentido, Ulpiano aceita ser uma regra natural a de que os filhos nascidos fora de um casamento legítimo seguem a condição da mãe, mas não vê impedimentos para alterá-la segundo as necessidades próprias do direito civil. Ora, como explicar esse desacordo entre os dois juristas sem que se aceite um sentido teórico, por menor que seja, na base da caracterização do direito natural?

Alguns comentadores procuraram contornar a questão considerando infundada a definição de direito natural de Ulpiano por não fazer sentido falar-se de direitos de animais. $\mathrm{O}$ jurista romano teria confundido as leis naturais da biologia, de caráter descritivo e não normativo, com as obrigações do direito natural (JOLOWICZ e NICHOLAS 1972). Deixando de lado o caráter talvez anacrônico da crí- 
tica, convém perguntar pela intenção do autor ao introduzir a distinção e pelos ganhos que ele objetivava. A principal motivação está na caracterização da condição natural dos seres vivos como iguais e livres. Esse é, de fato, o ponto de tensão entre a concepção bipartite de Gaio e a tripartite de Ulpiano. Ao tomar o ius gentium e o ius naturale como idênticos, Gaio não possui espaço para distinguir entre o que pertence à condição natural humana e aquelas regras que todos os povos aceitam como regendo as instituições sociais. Sendo assim, não há como negar que a escravidão, aceita por todos os povos, seja algo que faz parte da condição natural humana. Por sua vez, ao igualar homens e animais, Ulpiano busca descrever uma possível condição humana natural anterior ao ordenamento político, abrindo, assim, espaço justamente para a referida distinção. Provavelmente inspirado pela filosofia epicurista, Ulpiano defende a origem da associação política como resultado dos usos e necessidades da vida humana. Foi no momento de criação das comunidades políticas que teria surgido o direito dos povos. Anteriormente à introdução dessas regras, os seres humanos eram guiados apenas por seus instintos, assim como os animais, e, como eles, eram absolutamente livres. Foi o direito dos povos que introduziu a escravidão, a propriedade privada, bem como quase todas as formas de contrato. A tese de Ulpiano é reforçada por outros autores citados no Digesto. $\mathrm{O}$ jurista Florentino define a liberdade como a faculdade natural de se fazer o que se quer, ao menos que se esteja limitado pela força ou pela lei, e deixa claro que um tipo de limitação da liberdade natural é precisamente a condição de escravo, introduzida pelo direito dos povos. Já Hermógenes acrescenta que o direto dos povos introduziu as guerras, separou os povos, estabeleceu reinos, 
limitou os campos, introduziu o comércio, a compra e venda, o aluguel e todas as obrigações, exceto as do direito civil.

Ao introduzir a divisão tripartite do direito privado, Ulpiano não estava, portanto, preocupado apenas com o direito dos animais. Buscava antes mostrar que a liberdade e a igualdade são condições naturais de todos os seres humanos. Acrescentava ainda uma hierarquia de normas que sucessivamente qualificam e limitam a condição humana. $\mathrm{Na}$ esfera inferior, encontra-se o direito natural, correspondente ao estágio anterior às associações políticas, no qual todos os seres humanos são livres e iguais e não há propriedade privada. $\mathrm{Na}$ esfera intermediária está o direito dos povos, que, devendo responder às necessidades da vida em comunidade, alterou o direito natural, provavelmente por uma espécie de contrato social, e criou modos não naturais de relacionamentos, como as condições de senhores e escravos e a propriedade privada. O terceiro estágio, o mais forte, é formado pelo direito civil, o qual limita, por sua vez, o direito dos povos, e concede benefícios próprios a cada cidade, como o de ser cidadão romano. A maior força do direito civil aparece claramente no modo de interpretar a escravidão. Segundo Ulpiano, se alguém é livre em Roma e torna-se escravo em uma cidade estrangeira, ao voltar a Roma recupera sua liberdade, pois quem tem direitos políticos concedidos por Roma não os perde a não ser se Roma os retira.

Em suma, as divisões propostas por Gaio e Ulpiano parecem apontar para duas teorias distintas acerca da origem da associação política. Ao equiparar direito natural e direito dos povos, a concepção bipartite estaria comprometida com a tese segundo a qual a associação política é natural deven- 
do, portanto, aceitar que as regras pertencentes a toda associação política são igualmente naturais. Nesse caso, poderse-ia dizer que a escravidão é natural porque é encontrada entre todos os povos. Por outro lado, haveria, na concepção tripartite, espaço para se pensar a condição natural humana de forma independente da associação política. Sendo assim, os seres humanos seriam naturalmente livres, mesmo em se aceitando que todos os povos reconhecessem a escravidão.

As observações anteriores sugerem que o desacordo entre as concepções bipartite e tripartite do direito privado deve ser entendido como um desacordo teórico entre os juristas acerca do que deveria ser entendido por natureza. Se natural fosse exclusivamente "aquilo que, dentro da estrutura de um sistema, decorre como consequência da ordem normal”, então não haveria como apresentar o ponto de desacordo entre Gaio e Ulpiano. Além disso, ambas as divisões repercutem diretamente sobre o modo de compreender as noções de liberdade natural, escravidão e propriedade privada, noções cuja caracterização não pode ser feita independentemente de uma mínima teorização acerca da origem da associação política. Essa teorização, contudo, não consta explicitamente dos textos jurídicos e, certamente, não precisaria constar. Dito em outras palavras, independentemente das fontes extrajurídicas que teriam servido de base à apresentação das referidas divisões, fontes essas que não nos cabe aqui repertoriar, os textos jurídicos parecem supor teorias antagônicas acerca da origem da associação política, da origem da propriedade privada e da origem da escravidão.

Nada do que foi dito anteriormente, no entanto, é suficiente para refutar uma segunda tese, a saber, que em todo conflito entre o direito natural e o civil prevalece o último. 
Para tanto, passaremos em revista diversas passagens onde Gaio faz referência ao direito natural e o emprega para resolver problemas jurídicos.

\section{USOS PRÁTICOS DO DIREITO NATURAL}

Desde o início das Institutas, Gaio promete especificar quais normas pertencem ao ius gentium e quais são as especificamente romanas. Todavia, as referências ao direito dos povos não devem ser vistas como se o jurista buscasse evidenciar que o direito especificamente romano é o que melhor segue os ditames da razão natural. Não devemos, sobretudo, ler as Institutas como obra de um autor que vivesse em um momento no qual o direito romano passasse por uma crise de legitimidade que somente seria superada caso fosse possível fundar os preceitos especificamente romanos no direito racional dos povos. Ao contrário, ao fazer referência ao direito dos povos, Gaio pretende realçar as especificidades das instituições romanas. Estas são constantemente postas em evidência e mesmo apresentadas como superiores ao direito compartilhado por todas as nações, como se a genialidade romana fosse capaz de se alçar para além dos limites da razão natural. As Institutas evidenciam a maior força do direito civil e deixam claro que a intenção última de seu autor não é a de caracterizar um direito natural como origem e limite de toda obrigação jurídica. Não havia necessidade, para Gaio, de estabelecer tal fundamento. $\mathrm{O}$ recurso ao ius gentium tem por função complementar a legislação romana, estabelecendo-se assim uma relação de complementaridade entre as normas civis e naturais. Dessa forma, não causa surpresa a ênfase na força do direito civil que encontramos ao longo da obra. Por outro lado, seria 
igualmente um exagero desconsiderar completamente a função do direito natural para Gaio e reduzi-lo, como o fizeram alguns, à mera simplificação das normas romanas, como se nunca fosse possível apelar à razão natural para solucionar um conflito entre normas do direito civil.

A base das instituições romanas é o poder absoluto do paterfamilias (expressão que traduzimos por "chefe de família”) e cidadão dotado de plenos poderes. Isso aparece claramente na caracterização da persona como significando a capacidade para ser sujeito de direitos e deveres legais, podendo assim desempenhar um papel ativo na vida jurídica da cidade. Ora, em Roma a personalidade não pertence a todos no mesmo grau. A personalidade plena é privilégio que tem por condições: 1) do ponto de vista da liberdade, ser livre e não escravo; 2) do ponto de vista da cidade, ser cidadão e não latino ou pelegrino; 3) do ponto de vista da família, ser efetivamente chefe de família e não meramente em potência. Configuram-se assim, no seio da família romana, relações hierárquicas que podem ocorrer entre pessoas livres e escravos, bem como entre pessoas independentes (sui iuris) e dependentes (alieni iuris). Em ambos os casos, a relação possui fundamento no direito natural, mas são as matizes próprias da legislação civil que serão acentuadas $^{4}$. A relação natural de parentesco entre pais e filhos existe em todos os agrupamentos humanos, mas, diz Gaio, somente em Roma o poder absoluto do pai será o fundamento da família e da ordem social a ela ligada. $O$

\footnotetext{
${ }^{4}$ Gaio (Institutas, 1951, Livro I, §48-50): “48. Segue-se outra divisão a respeito do direito das pessoas. Pois umas são independentes; outras sujeitas a direito alheio. 49. Além disso, das sujeitas ao direito alheio (alieni iuris) umas estão sob o poder alheio; outras, in manu; e outras, in mancipio. 50. Vejamos agora as sujeitas a poder alheio; pois, conhecidas quais são essas pessoas, entenderemos logo quais as independentes (sui iuris)".
} 
paterfamilias pode abandonar os filhos, como abandonaria um animal ou uma coisa, vendê-los como escravos e castigálos inclusive com a morte.

Também a escravidão, como já vimos, é considerada uma instituição de direito natural e todos os povos reconheceriam tanto o poder de vida e de morte que o senhor possui sobre seus escravos como ainda que tudo aquilo que o escravo adquire pertence ao senhor. Com a evolução da sociedade romana, o direito civil teria conferido contornos específicos a esse direito natural, limitando o poder absoluto do senhor e proibindo o tratamento cruel e arbitrário de escravos por senhores romanos ou por todos que vivessem sob as leis de Roma:

52. Sob o poder estão os escravos, dos senhores. Esse poder vem do direito das gentes; pois, como podemos observar entre quase todos os povos, os senhores têm sobre os escravos o poder de vida e de morte; e tudo o que o escravo adquire para o senhor o adquire. 53. Mas atualmente, nem aos cidadãos romanos, nem a quaisquer outros homens, sob o império do povo romano, lhes é lícito castigar exageradamente e sem causa os seus escravos. Pois, em virtude de uma constituição do imperador Antonino, aquele que sem causa matar seu escravo cai sob a alçada da justiça, não menos que quem matar um escravo alheio. Mas esse mesmo imperador impôs uma coerção à excessiva crueldade dos senhores, pois, consultado por alguns governadores de província a respeito dos escravos que buscavam refúgio nos templos dos deuses e nas estátuas dos imperadores, determinou que, se se tiver como intolerável a sevícia dos senhores, sejam obrigados a vender seus escravos. E ambas essas disposições são justas, pois não devemos usar mal do nosso direito, sendo por isso que aos pródigos se lhes interdita a administração dos bens. (GAIO, Institutas, 1951, Livro I, §52-53)

Note-se, portanto, que quando Gaio compara o direito civil e o natural, ele não pretende encontrar nas normas compartilhadas por todos os povos um critério superior de racionalidade e de justiça. Também não defende que o di- 
reito romano deva espelhar ou basear-se em prescrições da ordem natural. Busca apenas ressaltar as particularidades das instituições romanas, chegando mesmo a admitir que o direito civil pode alterar o direito dos povos e que essa alteração pode significar um real avanço. A citação anterior parece, portanto, conferir razão à tese segundo a qual, nos conflitos entre o direito natural e o civil, prevaleceria sempre o último. Todavia, a situação não é tão simples. Em outras passagens, Gaio opõe-se às leis civis que lesariam o direito natural, como deixa claro em outra obra citada pelo Digesto, o Edito Provincial, na qual discute se a perda dos direitos civis pelo devedor implica que os credores não poderiam mais cobrar suas obrigações. Pelo direito civil, o sujeito que perde seus direitos perde igualmente a totalidade de seus bens e libera-se de suas dívidas. Contudo, no caso de obrigações que têm por objeto prestações naturais, como o dote, Gaio sustenta que o direito civil não destrói o que pertence ao direito natural, estando justificada a ação de cobrança.

Ainda segundo Gaio, o direito civil é próprio a cada cidade. Logo, as relações entre pessoas de cidades-Estado distintas devem regular-se pelo direito dos povos, o que será particularmente relevante no caso das relações comerciais. Como já observamos, o ganho de importância da noção de direito dos povos parece estar ligado à expansão romana. De início, as leis civis bastavam para regular os problemas internos à pequena cidade. Todavia, com o implemento de novas relações comerciais, sobretudo com Cartago, a lei romana não mais se mostrava apta a resolver todos os conflitos. Ademais, o direito romano estabelecia cláusulas bastantes estritas e modos solenes para realização de certos contratos e seria despropositado exigir de estrangeiros que 
os conhecessem e praticassem. Sendo assim, Gaio não vê alternativa senão basear a força vinculante dos pactos com estrangeiros no direito dos povos. Claro que não havendo estudo comparativo entre os diferentes sistemas jurídicos e que determinasse o que efetivamente é comum a todos os povos, a saída era estabelecer os elementos mínimos de uma relação e considerá-los pertencentes ao direito natural. Isso não significa, no entanto, que deveria sempre haver uma norma romana preexistente que fosse simplificada. Por exemplo, no caso das guerras, o problema seria determinar o fundamento jurídico para o direito sobre os bens dos vencidos. $\mathrm{O}$ jurista romano recorre aqui ao direito natural, pois a razão natural ensinaria ser do vencedor tudo o que é capturado do inimigo.

O direito dos povos não é usado apenas para falar do direito existente fora de Roma, mas pode ser empregado mesmo nos limites da cidade, como fica claro na seguinte passagem:

66. E adquirimos por razão natural (ratio naturalis) não apenas as coisas tornadas nossas pela tradição, mas também as adquiridas por ocupação, porque a ninguém pertenciam antes, como todas as coisas apanhadas da terra, no mar e no céu. 67. Por conseguinte, se apresarmos um animal bravio, uma ave ou um peixe, o assim apanhado torna-se logo nosso e entende-se nosso enquanto sujeito à nossa guarda; fugindo-lhe porém e voltando à liberdade natural, torna-se novamente do ocupante, pois deixou de ser nosso; e entende-se retornado à liberdade natural, quer escapando à nossa vista, que, embora à vista, sendo de difícil encalço. 68. Quanto aos animais habituados a ir e voltar, como as pombas, abelhas, veados, que costumam ir aos bosques e voltar, temos a regra tradicional: perdendo o hábito de voltar, deixam de ser nossos, tornando-se do ocupante; e consideram-se como tendo perdido o hábito de voltar perdendo disto o costume. 69. São também nossas, pela razão natural, as coisas tomadas aos inimigos. 70. E o acréscimo por aluvião à nossa propriedade é nosso pelo mesmo princípio; considera-se acres- 
centado por aluvião aquilo que o rio tão gradualmente junta à nossa terra, a ponto de não podermos avaliar quanto se acrescenta em cada momento do tempo; daí o dito vulgar segundo o qual se acrescenta por aluvião o que tão paulatinamente se junta, a ponto de nos escapar à vista. 71. Por isto, se o rio arrancar qualquer parte do teu fundo levando-o para o meu, esta parte continua tua. 72. Mas, nascendo uma ilha no meio do rio, é ela comum aos possuidores ribeirinhos de ambas as margens; não estando porém no meio do rio, pertence aos proprietários ribeirinhos da margem mais próxima. 73. Além disso, o construído em nosso terreno por outrem, embora este por sua conta o faça, torna-se nosso por direito natural (ius naturalis), porque a superfície acede ao solo. 74. Isto sucede maior razão relativamente à planta que alguém depõe em nosso terreno, mas de modo a lançar raízes na terra. 75. O mesmo se aplica ao grão semeado por outrem em nosso terreno. 76. Porém, se exigindo do outro o terreno ou edifício, não lhe quisermos pagar as despesas feitas com a construção, a sementeira ou as sementes, ele poderá repelir-nos com a exceção de dolo mau, sempre que possuidor de boa fé. 77 . Pela mesma razão, admite-se ser meu o que alguém tiver escrito em meu papel ou pergaminho, mesmo com letras de ouro, porque as letras acedem ao papel ou pergaminho. Por conseguinte, se eu exigir os livros ou pergaminhos, sem pagar o custo do escrito, poderei ser repelido pela exceção de dolo mau. 78. Mas se alguém pintar em minha tela, admite-se o contrário, pois entende-se que a tela acede à pintura. Encontra-se dificilmente a razão adequada desta diferença; em todo caso, segundo esta regra, se exigires como tua a pintura, possuída por mim, e não pagares o preço da tela, poderás ser repelido pela exceção de dolo mau; sendo tu o possuidor é consequente que se me dê ação contra ti; neste caso, a não ser pagando eu o custo da pintura, poderás repelir-me pela exceção de dolo mau, sempre que fores possuidor de boa fé. É evidente que se tu ou outrem houver subtraído a tela, cabe-me a ação de furto. (GAIO, Institutas, 1951, Livro II, § 66-78, tradução levemente corrigida)

Ou seja, tratando dos modos de aquisição da propriedade, Gaio distingue aqueles específicos do direito civil, como a usucapião, dos ditos naturais, cujo caso absolutamente inconteste é a ocupação entendida como aquisição por um modo originário de uma coisa sem dono (res nullius). Sempre que eventos implicam a aquisição de algo que 
nunca pertenceu a ninguém, como as ilhas surgidas no mar, as pedras preciosas encontradas em rios, o resultado da pesca ou da caça de um animal selvagem, a aquisição é vista sob o prisma do direito natural, ainda que a propriedade adquirida possa ser tratada e defendida nos limites do direto civil.

Também preconiza o direito natural que se duas coisas passam a estar indissoluvelmente ligadas, então o acessório segue o principal, de tal sorte que os produtos de uma propriedade devem pertencer ao proprietário. A regra aplica-se para o caso de uma casa construída na propriedade alheia. Segundo Gaio, a edificação faria parte da terra. Logo, pelo direito natural, a casa (acessório) pertenceria ao proprietário do terreno (principal). Situação um pouco diferente aconteceria se alguém plantasse em terras alheias. Ainda que aqui o acessório possa ser separado do principal, o produto pertence, por direito natural, ao proprietário das terras, cabendo, contudo, uma compensação se quem plantou agiu de boa-fé. Há casos, todavia, em que não é mais possível identificar o principal e o acessório, como quando alguém usa uvas alheias para fazer vinho. De quem é o produto final? Gaio afirma tratar-se de um caso que a razão natural deve resolver. No entanto, ele limita-se a apontar duas posições concorrentes. Uns sustentam que se deva olhar para a substância e atribuir ao proprietário dessa o resultado da obra. Outros defendem que se deva preferir o autor do trabalho e conferem ao proprietário da substância uma ação para recuperar o prejuízo. Importante observar que Gaio não toma posição acerca dessa questão, deixando a impressão de que a razão natural não tem solução para o caso ou 
de que ela pode não necessariamente oferecer uma única solução ${ }^{5}$.

Por fim, o direito natural é igualmente empregado para tratar de situações onde não há lei ou simplesmente não há necessidade de elaborar-se uma lei. Por exemplo, segundo o direito civil, é livre o nascido do casamento de pais livres que não perderam essa condição entre a gestação e nascimento da criança. Mas o que dizer do filho de um cidadão romano com uma mulher que, na época da concepção, era escrava e no momento do parto é livre? Segundo Gaio, a posição aceita segue a razão natural e considera aplicar-se, para filhos tidos fora do casamento, a condição da mãe no momento do parto. Logo, filhos de mãe livre nascem livres $^{6}$. Sobre isso não há polêmica, pois prevalece a razão. Ainda pelo direito dos povos, o filho de uma escrava e de um homem livre é escravo e o de uma mulher livre e de um escravo é livre. Mas o jurista chama a atenção para a necessidade de verificar-se se a legislação não alterou a lei natural, sinal explícito de que, em certas matérias, sobretudo as li-

\footnotetext{
${ }^{5}$ Gaio (Institutas, 1951, Livro II, \$79): "Também em matéria de especificação recorremos à razão natural. Assim, se de minha uva, azeitonas ou espigas fizeres vinho, azeite ou trigo, pergunta-se se é meu ou teu aquele vinho, azeite ou trigo. Igualmente, se de meu ouro ou prata fizeres um vaso, ou de minha madeira, um barco, armário ou assento; ou também se de minha lã fizeres um vestido, ou de meu vinho e mel um xarope, ou dos meus medicamentos um emplastro ou colírio, pergunta-se se é teu ou meu aquilo que fizeres com o que me pertence. Alguns pensam deva a matéria e a substância ser consideradas, isto é, que a coisa manufaturada pertence ao dono da matéria, e esta especialmente é a opinião de Sabino e Cássio. Outros consideram a coisa de quem a fez, e assim pareceu sobretudo aos autores da outra escola, mas também o proprietário da matéria e substância tem ação de furto contra quem lha subtrair, assim como the cabe uma condictio contra o ladrão; pois, embora não se possam reivindicar as coisas extintas, pode-se propor uma condictio contra os ladrões e certos outros possuidores".

${ }^{6}$ Gaio (Institutas, 1951, Livro I, §89): “89. E quanto à norma recebida pela qual, se uma escrava conceber de um cidadão romano e, depois de alforriada, parir, o nascido nasce livre, isso o é pela razão natural (ratio naturalis). Pois, os concebidos legitimamente ficam no estado que têm ao tempo do nascimento; portanto, os nascidos de mulher livre nascem livres, nem importa de quem a mãe os concebeu, enquanto era escrava; mas os concebidos legitimamente, ficam no estado do tempo da concepção".
} 
gadas à condição das pessoas e, em última instância, à cidadania romana, o direito civil fala mais alto do que o direito natural.

Abstract: In a very famous passage of his Institutes, the ancient jurist Gaius had divided the Roman Private Law in two parts: the Civil Law and the Law of People. The former is the Law created by the Roman people, whereas the latter is the Law followed by every nation. Despite its classical origin, there is some disagreement among specialists about the right way to interpret this distinction. By the beginning of the $20^{\text {th }}$ century, historians like Michel Villey had seen in this distinction the influence of Greek philosophy (Stoic but even Aristotelian) among the Roman jurists. But Levy and more recently Kelly have challenged this view and proposed that, in the roman period, philosophers and jurists had completely distinct notions of nature and natural law. The aim of this paper is not to prove the exact influence of Greek philosophy among jurists, but only to suggest that it is not possible to give an interpretation of the classical texts without ascribing to them a theoretical notion of the natural law.

Keywords: Roman Law, Natural Law, Gaius, nature.

\section{REFERÊNCIAS}

BASTIT, M. Essai sur le droit naturel de Gaius. Mémoire de DEA présenté et soutenu par M. Bastit, président du jury Michel Villey, Université de Paris II, 1977.

BURLE, E. Essai historique sur le développement de la notion de droit naturel dans l'antiquité classique. Trevoux, 1908.

CARBASSE, J.-M. Manuel d'introduction historique au droit. Paris: PUF, 2002.

CICERO. Laelius de Amicitia. Texte établi et traduit par R. Combès. Paris: Belles Lettres, 1983.

- De l'invention. Texte établi et traduit par Guy Achard. Paris: Belles Letres, 1994. 
to. Traducido al castellano del latino por Ildefonso L. García del Corral. Barcelona: Jaime Molinas Editor, 1889.

DOUZINAS, C. Human rights and empire: the political philosophy of cosmopolitanism. Routledge: New edition, 2007.

FASSÒ, G. Storia della filosofia del diritto. I. Antichità e medioevo. Edizione aggiornata a cura di Carla Faralli. Roma: Gius Laterza \& Figli Spa, 2005.

FLAVIUS PETRUS SABBATIUS JUSTINIANUS, Institutas do Imperador Justiniano. Tradução de J. Cretella Jr. e Agnes Cretella. São Paulo: RT, 2000.

. Justinians's Institutes. Translated with an introduction by Peter Birks and Grant McLeod with the latin text of Paul Krueger. Nova Iorque: Cornell University Press, 1987.

GAIO. Institutas. In: CORREIA, A.; SCIASCIA, G. Manual de Direito Romano. v. II. Institutas de Gaio e de Justiniano vertidas para o português em confronto com o texto latino. São Paulo: Saraiva, 1951.

- Institutes. Texte établi et traduit pas Julien Reinach, cinquième tirage revu et corrigé par M. Ducos. Paris: Les Belles Lettres, 2003.

. The Institutes of Gaius. Translated with an introduction by W. M. Gordon and O. F. Robinson with the latin text of Seckel and Kuebler. Nova Iorque: Cornell University Press, 1988.

GIULIANI, A. Il concetto di prova. Contributo alla logica giuridica. Milano, 1971. 
GOYARD-FABRE, S.; SEVE, R. Les grandes questions de la philosophie du droit. Paris: PUF, 1986.

JOLOWICZ, H. F.; NICHOLAS, B. Historical introduction to the study of Roman Law. Cambridge: University Press, 1972.

KELLY, J. M. Uma breve história da teoria do direito ocidental. Tradução de Marylene Pinto Miclael. São Paulo: Martins Fontes, 2010.

LOPES, J. R. L. O Direito na história. Lições introdutórias. São Paulo: Max Limonad, 2000.

MACROBIO. Commentaire au Songe de Scipion. Macrobe, texte établi, traduit et commenté par M. ArmisenMarchetti. Paris: Belles Lettres, 2001.

METZGER, E. A companion to Justinian's Institutes. New York: Cornell University Press, 1998.

NICHOLAS, B. Introduction to Roman Law. Oxford: Clarendon Press, 1962.

PALLASSE, M. Cicéron et les sources des droits. Paris, 1945.

PEZZELLA, M. C. C. Propriedade privada no Direito Romano. Porto Alegre: Sérgio Antônio Fabris Editor, 1998.

PRODI, P. Uma história da justiça. Do pluralismo dos foros ao dualismo moderno entre consciência e direito. Tradução de Karina Jannini. São Paulo: Martins Fontes, 2005.

SENN, F. De la justice et $d u$ droit. Explication de la définition traditionnelle de la justice suivie d'une étude sur la distinction du Ius Naturale et du Ius Gentium. Paris: Sirey, 1927. 
STEIN, P. Roman Law in European history. Cambridge: Cambridge University Press, 1999.

VILLEY, M. Deux conceptions du droit naturel dans l'antiquité. Revue Historique de Droit Français et Etranger, n. 4, p. 475-497, 1953.

WIRSZUBSKI, CH. Libertas as a political idea at Rome during the late republic and early principate. Cambridge, 1960. 